УДК 543.544.5.068.7:[663.2+582.912.46:664.859.2]

\title{
ПРИМЕНЕНИЕ ВИНА КАБЕРНЕ-СОВИНЬОН ДЛЯ ОПРЕДЕЛЕНИЯ ИДЕНТИФИКАЦИОННЫХ ХАРАКТЕРИСТИК З-О-ГЛЮКОЗИДОВ АНТОЦИАНИДИНОВ ПРИ АНАЛИЗЕ СОСТАВА АНТОЦИАНОВ В ПАСТЕ ИЗ ЯГОД ЧЕРНИКИ
}

\author{
(C) И.В. Ходаков \\ Институт стоматологии Национальной академии медицинских наук \\ Украины, ул. Ришельевская, 11, Одесса, 65026 (Украина), \\ e-mail: hodakovigor@gmail.com
}

\begin{abstract}
Рассмотрена возможность использования вина винограда сорта Каберне-Совиньон (Vitis vinifera L.) для получения характеристик 3-О-глюкозидов дельфинидина, цианидина, петунидина, пеонидина и мальвидина с целью идентификации этих антоцианов в ягодах и пасте черники обыкновенной (Vaccinium myrtillus L.) в BЭЖX при 530 нм. Известная очередность пиков антоцианов на хроматограммах экстрактов ягод черники при использовании обращенофазовых колонок типа С18 позволяет применять идентифицированные 3-О-глюкозиды в качестве опорных веществ для установления остальных гликозидов антоцианидинов (галактозидов и арабинозидов) в пасте из ягод черники.

Ключевые слова: вино Каберне-Совиньон, черника обыкновенная, Vaccinium myrtillus, паста черники, ВЭЖХ, антоцианы, 3-О-глюкозиды антоцинидинов.
\end{abstract}

\section{Введение}

Растения рода Vaccinium L. (сем. Ericaceae), в том числе и черника обыкновенная (V. myrtillus L.), вызывают повышенный интерес в связи с широким спектром лечебно-профилактических свойств их плодов. Высокое содержание биологически активных полифенолов обусловливает антиоксидантное, антимикробное, антидиабетическое, противовоспалительное, антивирусное, вазопротекторное действия, способность ингибировать рост опухолей [1]. Кроме того, недавно обнаружены гепатопротекторные свойства черники [2]. Преобладание тех или иных свойств черники может зависеть от количественного соотношения отдельных групп и веществ полифенолов, среди которых весомую долю занимают антоцианы - гликозилированные формы антоцианидинов, представляющие собой производные 2-фенилбензопирилия - от 2,7 до 6 мг/г влажной массы ягоды [3-6], до 86,9\% от общей массы полифенолов [5].

В ягоде черники обнаружено 15 основных антоцианов, являющихся гликозидами пяти антоцианидинов: дельфинидина, цианидина, петунидина, пеонидина и мальвидина [7]. Каждый антоцианидин представлен тремя гликозидными формами: галактозидом, глюкозидом и арабинозидом. Известно, что общее содержание антоцианов, а также соотношение отдельных антоцианов в значительной степени зависят от условий произрастания растений. Полифенольный состав ягод черники варьирует в разных странах $[3,5]$ и даже в пределах одной страны [4-6, 8], что обусловливает, например, различия в антиоксидантных свойствах ягод черники из разных популяций $[4,9]$. Знание точного состава полифенолов, в частности антоцианов, позволит выбирать наиболее выгодные биотопы для сбора лекарственного сырья, а также оценить качество сырья и продукции, стандартизировать их.

Наиболее точным качественным и количественным анализом веществ признана ВЭЖХ, в которой идентификацию веществ проводят по абсорбционным пикам на хроматограммах путем сравнения времени

Ходаков Игорь Владимирович - научный сотрудник лаборатории биохимии, тел.: +38(048) 728-24-63, e-mail: hodakovigor@gmail.com удерживания исследуемых веществ с аналогичным показателем для стандартов [10]. Существенной проблемой идентификации веществ в ВЭЖХ является 
ограниченная доступность стандартов. Фактически каждому пику на хроматограмме для его идентификации должен соответствовать стандарт. Усложняет идентификацию и недостаточно качественное разделение веществ, приводящее к наложению или совпадению пиков. В то же время в случае анализа растительного экстракта, основной состав которого уже известен и опубликован другими исследователями, задача может сводиться к определению лишь некоторых (опорных) веществ в пробе, относительно расположения пиков которых можно идентифицировать другие вещества. Определять вещества антоцианового комплекса можно на основе анализа относительного удерживания, позволяющего определять время удерживания антоцианов в зависимости от состава элюента относительно ограниченного количества стандартов [11-13]. Также в качестве стандартов можно использовать растительное сырье с известным составом, при анализе которого картина расположения пиков на хроматограммах повторяется даже при изменении условий анализа и позволяет однозначно и точно получить время удерживания для некоторых значимых веществ [14]. Так, для получения характеристик 3-О-глюкозидов антоцианов удобно использовать вино красных сортов винограда (Vitis vinifera L.). В ягодах и вине в зависимости от технической оснащенности ВЭЖХ обнаруживается от 21 до 40 антоцианов [15-18]. Однако многочисленные исследования по составу вин и ягод винограда с использованием обращенно-фазовых колонок С18 [19-28] показали, что характерная картина расположения пиков на хроматограммах позволяет точно идентифицировать на хроматограммах в диапазоне 520-530 нм дельфинидин-3-О-, цианидин-3-О-, петунидин-3-О-, пеонидин-3-О- и мальвидин-3-Оглюкозиды, по времени удерживания которых можно идентифицировать аналогичные глюкозиды в другом растительном материале, где их присутствие известно. При использовании литературных данных о составе исследуемого материала необходимо, чтобы тип хроматографических колонок и длина волны в собственных исследованиях совпадали с описанными в литературе, что гарантирует постоянство очередности выхода веществ независимо от остальных условий хроматографирования (состав и скорость движения элюента, температура, градиент).

Цель работы - исследовать возможность использования красного виноградного вина КабернеСовиньон в ВЭЖХ для определения времени удерживания глюкозидов дельфинидина, цианидина, петунидина, пеонидина и мальвидина с последующей идентификацией этих антоцианов в пасте черники.

\section{Экспериментальная часть}

Для определения времени удерживания 3-О-глюкозидов дельфинидина, цианидина, петунидина, пеонидина и мальвидина использовали вино Каберне-Совиньон производства ННЦ «Институт виноградарства и виноделия им. В.Е. Таирова НААН Украины». Перед анализом в образец вина добавляли 96\%-ный этиловый спирт до его концентрации $60 \%$ в пробе.

В качестве образца для исследования использовали пасту из ягод черники обыкновенной производства НПП «Институт «Текмаш» (Херсон, Украина). Экстракты пасты для анализа готовили путем настаивания в течение 2 ч с учетом ее влажности из расчета 1 г сухого сырья на 20 мл 60\%-ного этанола. Концентрация этанола в экстракте и длительность экстракции выбраны в соответствии с методикой [29].

В отфильтрованных экстрактах вина и пасты черники проводили анализ полифенолов методом ВЭЖХ на хроматографической системе Shimadzu (Япония) с использованием обращенно-фазовой колонки Microsorb-MV C18 (длина 150 мм, диаметр 4,6 мм, зерно сорбента 5 мкм). Элюент - система метанол и 0,9\%-ный раствор фосфорной кислоты. Режим хроматографирования - градиентный. Начальное соотношение компонентов элюента - $1: 9$. Соотношение метанола и раствора фосфорной кислоты в ходе анализа изменялось по ранее разработанной схеме [30] в сторону повышения содержания метанола от 10 до $80 \%$. Длительность анализа - 75 мин. Скорость движения элюента - 0,5 мл/мин, температура колонки - $40{ }^{\circ} \mathrm{C}$, объем вводимой пробы - 5 мкл.

Анализ проб вина проводили при длине волны 530 нм, пасты черники - при 225, 255, 286, 350 и 530 нм.

Для повышения точности идентификации антоцианов в пасте черники определяли спектральные характеристики их пиков по ранее разработанной методике [31, 32], согласной которой каждое исследуемое вещество характеризовалось тремя значениями высоты его пика на хроматограммах при длинах волн 255 , 286 и 350 нм, приведенной к высоте пика при 225 нм.

Оценку содержания антоцианов в пасте черники проводили по калибровке зависимости «площадь пика - содержание» для стандарта цианидина $\left(r^{2}=0,9979\right)$ при 286 нм. Данная длина волны выбрана ввиду того, что некоторые антоцианы при 530 нм характеризуются низкой интенсивностью поглощения света, вследствие чего их пики слабо выражены вплоть до полного исчезновения. 


\section{Результаты и их обсуждение}

Анализ данных литературы о составе антоцианов в вине и экстрактах ягод примерно 80 сортов красного винограда из разных стран [16, 19, 21-25, 27, 28, 33-36], в том числе и сорта Каберне-Совиньон [20, 24, 27, 35-40], показал присутствие следующих основных групп гликозидов: глюкозиды, ацетилглюкозиды, кумарил-глюкозиды, кофеил-глюкозиды. Каждая из этих групп может быть представлена моно- и 3,5-дигликозидами. Несмотря на разнообразие гликозидных форм, существенным содержанием отличается лишь часть моногликозидов, и среди них - интересующие нас 3-О-глюкозиды. Пики этих глюкозидов проявляются на хроматограммах раньше других моногликозидов и всегда при использовании колонок типа С18 при длине волны 520-530 нм расположены в следующем порядке: дельфинидин-, цианидин-, петунидин-, пеонидин- и мальвидин-глюкозид. При этом соблюдается четкая закономерность для соотношения высот пиков глюкозидов: наибольшая высота - у пика глюкозида мальвидина, наименьшая - у глюкозида цианидина (рис. 1). Используя отмеченные закономерности в очередности пиков глюкозидов и их высот, для идентификации этих веществ в вине предлагаем применять следующий несложный алгоритм: при 530 нм среди первых ранних пиков на хроматограмме выделяют пять наиболее крупных; самый высокий из них - глюкозид мальвидина, самый низкий - глюкозид цианидина; между ними - глюкозид петунидина (первый крупный пик справа от глюкозида цианидина) и глюкозид пеонидина (первый крупный пик слева от глюкозида мальвидина). Первый крупный пик слева от пика глюкозида цианидина соответствует глюкозиду дельфинидина. Пик глюкозида мальвидина - обычно самый высокий среди всех пиков на хроматограмме. Возможно присутствие между указанными пиками пиков дигликозидов, но ввиду крайне низкого содержания этих веществ их высоты ниже интересующих нас пиков. Следует отметить, что к некоторым сортам винограда нельзя применять предложенный алгоритм идентификации глюкозидов изза значительного содержания дигликозидов (сорта Montepulciano, Clinton, Regent [26, 39, 41] или даже присутствия глюкозидов пеларгонина (сорт Yan73 - гибрид Muscat Hamburg x Alicante Bouschet) [42].

На рисунке 2 представлена хроматограмма, являющаяся результатом выполненного нами анализа вина Каберне-Совиньон. Сопоставление хроматограмм на рисунках 1 и 2 показывает абсолютное сходство в очередности расположении пяти крупных ранних пиков. В соответствии с предложенным выше алгоритмом эти пики идентифицировали как 3-О-глюкозиды вышеперечисленных антоцианидинов. Пик глюкозида мальвидина имел сопоставимую высоту с другими пиками из-за неполного разделения некоторых ацетил- и кумарил-глюкозидов, раположенных позже 3-О-глюкозидов: в одном из пиков слились пики трех веществ, в другом - пяти (рис. 2). В таблице представлено соответствие веществ в пасте черники глюкозидам в вине по времени удерживания.

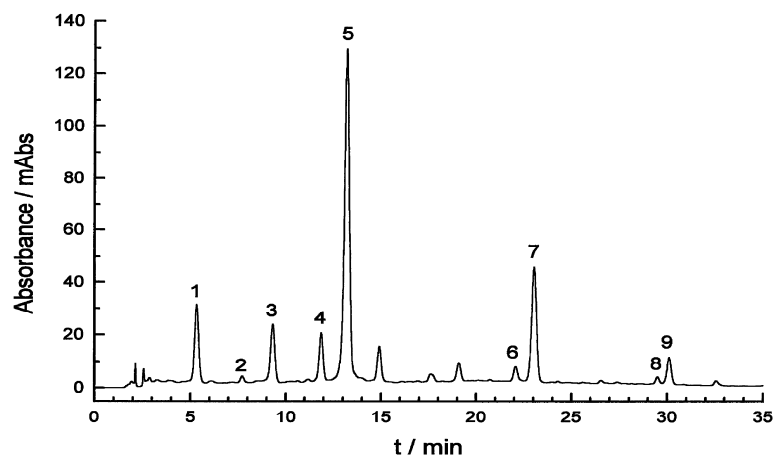

Рис. 1. Типичная хроматограмма красного вина при 530 нм (по данным [16]): 1 - дельфинидин-3О-глюкозид; 2 - цианидин-3-О-глюкозид; 3 - петунидин-3-О-глюкозид; 4 - пеонидин-3-Оглюкозид; 5 - мальвидин-3-О-глюкозид; 6-9 - ацетил- и кумарил-глюкозиды антоцианов

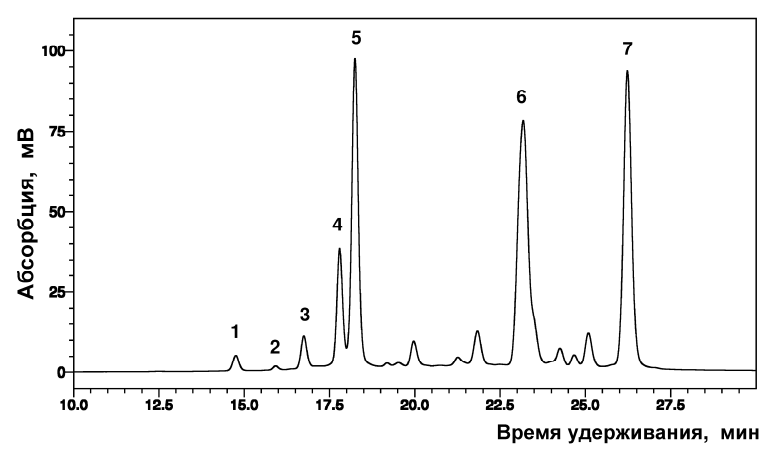

Рис. 2. Хроматограмма вина Каберне-Совиньон при 530 нм: 1 - дельфинидин-3-О-глюкозид; 2 - цианидин-3-О-глюкозид; 3 - петунидин-3-Оглюкозид; 4 - пеонидин-3-О-глюкозид; 5 - мальвиндин-3-О-глюкозид; 6 - совокупность пеонидин-3-О-ацетил-, мальвидин-3-О-ацетил, дельфинидин-3-О-кумарил- и мальвидин-3-Окофеил-глюкозидов; 7 - совокупность пеонидин-3О- и мальвидин-3-О-кумарил-глюкозидов 
Идентификационные характеристики антоцианов пасты черники и вина Каберне-Совиньон

\begin{tabular}{|c|c|c|c|c|c|c|c|}
\hline \multirow[t]{2}{*}{ Пик } & \multirow{2}{*}{$\begin{array}{c}\text { T } \\
\text { (паста } \\
\text { черники) }\end{array}$} & \multirow{2}{*}{$\begin{array}{c}\mathrm{T} \\
\text { (вино) }\end{array}$} & \multirow{2}{*}{$\begin{array}{c}\text { Стандарты } \\
\text { (вино) }\end{array}$} & \multirow{2}{*}{$\begin{array}{c}\text { Идентификация } \\
\text { антоцианов пасты } \\
\text { черники }\end{array}$} & \multicolumn{3}{|c|}{$\begin{array}{c}\text { Спектральные характеристики антоцианов } \\
\text { пасты черники }\end{array}$} \\
\hline & & & & & $\mathrm{h}_{255}$ & $\mathrm{~h}_{286}$ & $\mathrm{~h}_{350}$ \\
\hline 1 & 14,41 & & & дельф-3-О-гал & 0,462 & 0,661 & 0,137 \\
\hline 2 & 14,83 & 14,76 & дельф-3-О-глк & дельф-3-О-глк & 0,457 & 0,659 & 0,132 \\
\hline 3 & 15,43 & & & циан-3-О-гал & 0,493 & 0,894 & 0,108 \\
\hline A & 15,80 & & & дельф-3-О-арб & 0,461 & 0,768 & 0,128 \\
\hline 4 & 15,92 & 15,92 & циан-3-О-глк & циан-3-О-глк & 0,497 & 0,827 & 0,129 \\
\hline 5 & 16,43 & & & циан-3-О-арб & 0,041 & 0,059 & 0,013 \\
\hline 6 & 16,82 & 16,75 & пет-3-О-глк & пет-3-О-глк & 0,467 & 0,734 & 0,133 \\
\hline B & 17,12 & & & пеон-3-О-гал & 0,621 & 0,627 & 0,357 \\
\hline 7 & 17,39 & & & пет-3-О-арб & 0,815 & 0,502 & 0,701 \\
\hline 8 & 17,81 & 17,80 & пеон-3-О-глк & пеон-3-О-глк & 0,455 & 0,761 & 0,103 \\
\hline 9 & 18,01 & & & мальв-3-О-гал & 0,356 & 0,823 & 0,153 \\
\hline 10 & 18,32 & 18,25 & мальв-3-О-глк & мальв-3-О-глк & 0,417 & 0,625 & 0,115 \\
\hline 11 & 18,76 & & & н/и антоциан & 0,350 & 0,954 & 0,130 \\
\hline 12 & 19,37 & & & мальв-3-О-арб & 0,707 & 0,665 & 0,387 \\
\hline
\end{tabular}

Примечания: Т - время удерживания веществ, мин; дельф - дельфинидин, циан - цианидин, пет - петунидин, пеон пеонидин, мальв - мальвидин, гал - галактозид, глк - глюкозид, арб - арабинозид, н/и антоциан - неидентифицированный антоциан; $\mathrm{h}_{255}, \mathrm{~h}_{286}$ и $\mathrm{h}_{350}$ - относительные высоты пиков при 255, 286 и 350 нм; А - пик, частично совпадающий с пиком 4; В - пик антоциана, выявленный в ультрафиолетовом диапазоне (рис. 5). Номера пиков соответствуют пикам на рисунках 4 и 5.

Пики идентифицированных в пасте черники глюкозидов использовали в качестве опорных для определения остальных антоцианов. Известны состав и порядок расположения на хроматограммах пиков 15 основных антоцианов ягод черники при использовании колонок типа С18 в диапазоне от 520 до 530 нм $[3,43]$. На рисунке 3 представлена хроматограмма смеси стандартов антоцианов ягод черники по данным [43], на рисунке 4 - полученная нами хроматограмма экстракта пасты черники при 530 нм с 12 хорошо различимыми идентифицированными пиками. При сопоставлении времени удерживания глюкозидов в вине с веществами в пасте черники (см. табл.) было выяснено, что глюкозиды дельфинидина, петунидина, пеонидина и мальвидина представлены на хроматограмме обособленными, хорошо разделенными пиками (пики $2,6,8$ и 10). Пик глюкозида цианидина совмещен с пиками других антоцианов (пик 4), что свидетельствует о недостаточной селективности данного метода хроматографирования. Тем не менее расположение пика глюкозида цианидина определено точно, и выяснен состав комплексного пика. Всего при 530 нм идентифицировано 11 гликозидов антоцианов, имеющих обособленные пики, и определено положение трех гликозидов, пики которых совпали с пиками других гликозидов (рис. 4).

Еще один антоциан идентифицировали с применением спектральных характеристик. Анализ спектральных характеристик пиков в промежутке времени удерживания от 14 до 20 мин в ультрафиолетовом диапазоне (см. табл.) показал, что большинство идентифицированных антоцианов имеют сходные параметры. Из совокупности веществ обнаружили два, имеющих близкие спектральные характеристики, но отличающихся от параметров других антоцианов (пики В и 12) (см. табл.). Одно из веществ (пик 12) - уже установленный арабинозид мальвидина. Согласно данным по спектрам поглощения [3], арабинозид мальвидина и галактозид пеонидина при 520-530 нм имеют минимальную среди антоцианов интенсивность поглощения. Пик арабинозида мальвидина различим на хроматограмме при 530 нм ввиду значительного содержания этого вещества, пик галактозида пеонидина при этой длине волны отсутствует. Учитывая вышеперечисленные свойства, пик галактозида пеонидина (пик В) был обнаружен на хроматограмме в ультрафиолетовом диапазоне (при 225, 255 и 286 нм) (рис. 5). Первоначально его идентифицировали как антоциан, затем, согласно очередности расположения пиков стандартов, как галактозид пеонидина.

Таким образом, в пасте черники были идентифицированы: 3-О-галактозиды дельфинидина, цианидина, пеонидина, мальвидина; 3-О-глюкозиды дельфинидина, цианидина, петунидина, пеонидина, мальвидина, 3-О-арабинозиды цианидина, петунидина, мальвидина (12 антоцианов, пики которых были обособлены), а также определено наиболее вероятное положение пиков 3-О-арабинозидов дельфинидина и пеонидина и 3-О-галактозида петунидина (3 антоциана, пики которых совпали с пиками других гликозидов). 
Рис. 3. Хроматограмма стандартов антоцианов ягод черники при 530 нм (по данным [40]): 1 - дельфинидин-3-О-галактозид; 2 - дельфинидин3-О-глюкозид; 3 - цианидин-3-О-галактозид; 4 - дельфинидин-3-О-арабинозид; 5 - цианидин-3О-глюкозид; 6 - петунидин-3-О-галактозид; 7 - цианидин-3-О-арабинозид; 8 - дельфинидин; 9 - петунидин-3-О-глюкозид; 10 - пеонидин-3-Огалактозид; 11 - петунидин-3-О-арабинозид; 12 - пеонидин-3-О-глюкозид; 13 - мальвидин-3-Огалактозид; 14 - пеонидин-3-О-арабинозид; 15 - цианидин; 16 - мальвидин-3-О-глюкозид; 17 - мальвидин-3-О-арабинозид; 18 - петунидин; 19 - пеонидин; 20 - мальвидин

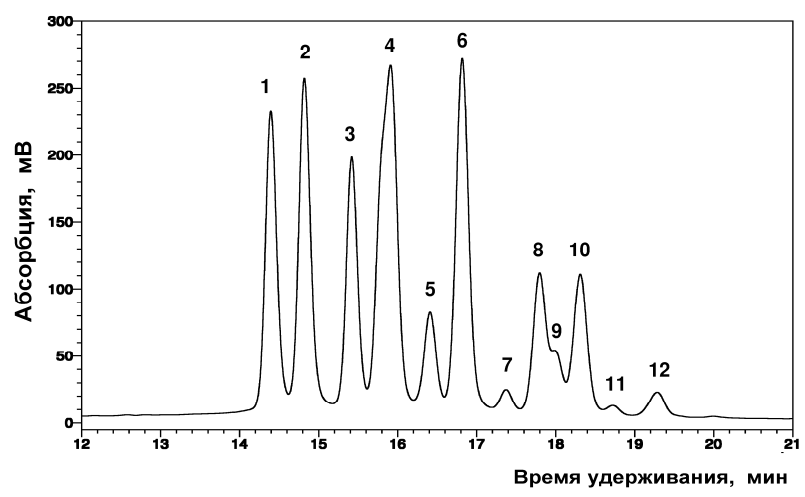

Рис. 4. Хроматограмма экстракта пасты черники при 530 нм (номера пиков соответствуют пикам в таблице)
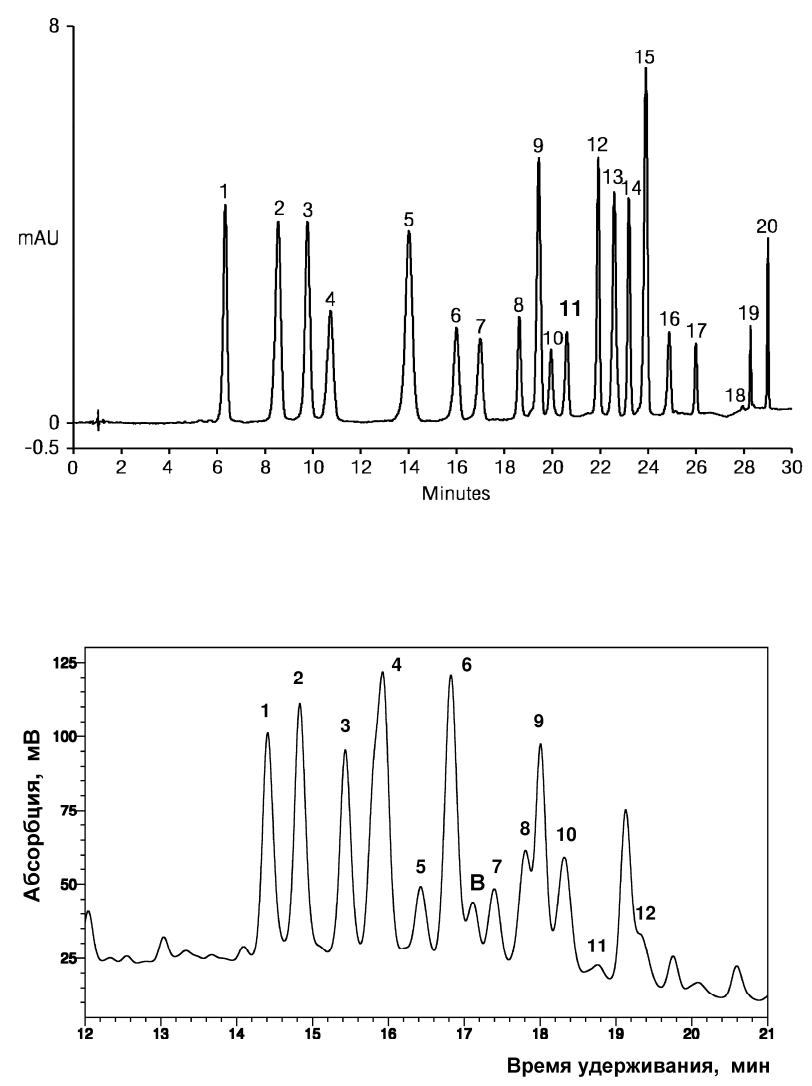

Рис. 5. Хроматограмма экстракта пасты черники при 255 нм: В - пеонидин-3-О-галактозид (номера пиков соответствуют пикам в таблице)

Используя калибровку «площадь пика - содержание» для цианидина при 286 нм оценили общее содержание в пасте черники антоцианидинов. Оно составило 2,98 мг/г влажной пасты (или 20,57 мг/г высушенной пасты). Данная оценка имеет определенную погрешность. Тем не менее, полученные значения близки к минимальному содержанию антоцианов в ягодах черники. Соотношение антоцианов следующее: гликозиды дельфинидина - 25,8\%, цианидина - 30,9\%, петунидина - 13,3\%, пеонидина - 7,7\%, мальвидина - 22,3\%.

Для более точного определения содержания антоцианов в исследуемых экстрактах следует использовать вино Каберне-Совиньон от производителей, практикующих регулярный химический анализ своей продукции. По значениям содержания 3-О-глюкозидов и площадям их пиков на хроматограммах вина можно рассчитать параметры зависимости «площадь пика - содержание» и использовать их для определения содержания этих глюкозидов в исследуемом материале, а также для оценки содержания остальных гликозидов (арабинозидов, галактозидов).

\section{Выводы}

1. Предложен алгоритм идентификации 3-О-глюкозидов дельфинидина, цианидина, петунидина, пеонидина и мальвидина в ВЭЖХ на хроматограммах вина Каберне-Совиньон при 530 нм, время удерживания которых можно использовать для идентификации этих антоцианов в пасте из ягод черники.

2. Известная очередность пиков антоцианов на хроматограммах экстрактов ягод черники при работе с обращенно-фазовыми колонками типа С18 при 530 нм позволяет использовать идентифицированные 3-Оглюкозиды в качестве опорных веществ для идентификации остальных гликозидов антоцианов (галактозидов и арабинозидов) в пасте из ягод черники. 


\section{Список литературы}

1. Su Z. Anthocyanins and flavanoids of Vaccinium L. // Pharmaceutical Crops. 2012. N3. Pp. 7-37.

2. Левицкий А.П., Осипенко С.Б., Цисельский Ю.В., Демьяненко С.А., Макаренко О.А., Селиванская И.А. Гепатопротекторные свойства пасты из плодов черники при экспериментальном токсическом гепатите и кишечном дисбиозе // Фітотерапія. Часопис. 2009. №3. С. 26-30.

3. Burdulis D., Ivanauskas L., Dirsė V., Kazlauskas S., Ražukas A. Study of diversity of anthocyanin composition in bilberry (Vaccinium myrtillus L.) fruits // Medicina (Kaunas). 2007. Vol. 43, N12. Pp. 971-977.

4. Burdulis D., Šarkinas A., Jasutieneė I., Stackevičiene E., Nikolajevas L., Janulis V. Comparative study of anthocyanin composition, antimicrobial and antioxidant activity in bilberry (Vaccinium myrtillus L.) and blueberry (Vaccinium corymbosum L.) fruits // Acta Poloniae Pharmaceutica - Drug Res. 2009. Vol. 66, N4. Pp. 399-408.

5. Jovančević M., Balijagić J., Menković N., Šavikin K., Zdunić G., Janković T., Dekić-Ivanković M. Analysis of phenolic compounds in wild populations of bilberry (Vaccinium myrtillus L.) from Montenegro // J. Med. Plants Res. 2011. Vol. 5, N6. Pp. 910-914.

6. Rimpapa Z., Toromanovic J., Tahirovic I., Šapčanin A., Sofic E. Total content of phenols and anthocyanins in edible fruits from Bosnia // Bosnian J. Basic Med. Sciences. 2007. Vol. 7, N2. Pp. 119-122.

7. Lätti A.K., Riihinen K.P., Kainulainen P.S. Analysis of anthocyanin variation in wild populations of bilberry (Vaccinium corymbosum L.) in Finland // J. Agricult. and Food Chemistry. 2008. N56. Pp. 190-196.

8. Burdulis D., Ivanauskas L., Jakštas V., Janulis V. Analysis of anthocyanin content in bilberry (Vaccinium myrtillus L.) fruit crude drugs by high-performance liquid chromatography method // Medicina (Kaunas). 2007. Vol. 43, N7. Pp.568-574.

9. Veres B.V., Dorica B. Researches regarding antioxidant capacity in callus cultures and native plants of Vaccinium myrtillus L. local populations // J. Horticulture, Foresty and Biotechnology. 2011. Vol. 15, N3. Pp. 94-98.

10. Сапрыкин Л.В. Высокоэффективная жидкостная хроматография. Харьков, 2007. 228 с.

11. Дейнека В.И., Григорьев А.М., Староверов В.М., Борзенко О.Н. Инкрементный подход в анализе антоцианов // Химия природных соединений. 2003. №2. С. 137-139.

12. Дейнека В.И., Григорьев А.М. Определение антоцианов методом ВЭЖХ. Некоторые закономерности удерживания // Журн. аналит. химии. 2004. Т. 59, №3. С. 305-309.

13. Дейнека В.И., Григорьев А.М. Относительный анализ удерживания гликозидов цианидина // Журн. физич. химии. 2004. Т. 78, №5. С. 923-926.

14. Дейнека В.И., Григорьев А.М., Дейнека Л.А., Шапошник Е.И., Староверов В.М. Исследование антоцианов черники в плодах и препаратах на ее основе методом ВЭЖХ // Заводская лаборатория. Диагностика материалов. 2006. Т. 72, №3. С. 16-20.

15. Wulf L.W., Nagel C.W. High-pressure liquid chromatographic separation of anthocyanins of Vitis vinifera // Am. J. Enol. Vitic. 1978. N29. Pp. 42-49.

16. Heier A., Blaas W., Droß A., Wittkowski R. Anthocyanin analysis by HPLC/Esi-MS // Am. J. Enol. Vitic. 2002. N53. Pp. 78-86.

17. Flamini R. Mass spectrometry in grapes and wine chemistry. Part 1: Polyphenols // Mass spectrometry Reviews. 2003. N22. Pp. 218-250.

18. He F., Mu L., Yan G.-L., Liang N.-N., Pan Q.-H., Wang J., Reeves M.J., Duan Ch.-Q. Biosynthesis of anthocyanins and their regulation in colored grapes // Molecules. 2010. N15. Pp. 9057-9091.

19. Hohnová B., Štaviková L., Karásek P. Determination of anthocyanins in red grape skin by pressurized fluid extraction and HPLC // Czech J. Food Sci. Vol. 26. Special Issue. Ph. S39-S42.

20. Berente B., Garcia D. De la C., Reichenbächer M., Dancer K. Method development for the determination of anthocyanins in red wines by high-performance liquid chromatography and classification of German red wines by means of multivariate statistical methods. // J. Chrom. A. 2000. N871. Pp. 95-103.

21. Durst R.W., Wrolstad R.E. Separation and characterization of anthocyanins by HPLC // In: Wrolstad R.E. (Ed.) Currant protocols in food analytical chemistry. New York: Wiley, 2001. Unit F1.3.1-1.3.13.

22. Boss P.K., Davis Ch., Robinson S.P. Analysis of the expression of anthocyanin pathway genes in developing Vitis vinifera L.cv Shiraz grape berries and the implications for pathway regulation // Plant Physiol. 1996. N111. Pp. 1059-1066.

23. Revilla E., Ryan E.M. Analysis of several phenolic compounds with potential antioxidant properties in grape extracts and wines by high-performance liquid chromatography-photodiode array detection without sample preparation // J. Chrom. A. 2000. N881. Pp. 461-469.

24. Revilla E., Garcia-Beneytez E., Cabello F., Martin-Ortega G., Ryan J.-M. Value of high-performance liquid chromatographic analysis of anthocyanins in the differentiation of red grape cultivars and red wines made from them // J. Chrom. A. 2001. N915. Pp. 53-60.

25. Muńoz S., Mestres M., Busto O., Guasch J. Determination of some flavan-3-ols and anthocyanins in red grape seed and skin extracts by HPLC-DAD: validation study and response comparison of different standards // Analitica Chimica Acta. 2008. N628. Pp. 104-110.

26. Pati S., Liberatore M.T., Gambacorta G., Antonacci D., La Notte E. Rapid screening for anthocyanins and anthocyanin dimmers in crude grape extracts by high performance liquid chromatography coupled with diode array detection and tandem mass spectrometry // J. Chrom. A. 2009. N1216. Pp. 3864-3868. 
27. Kallithraka S., Mohdaly A.-A.A., Markis D.P., Kefalas P. Determination of major anthocyanin pigments in Helenic native grape varieties (Vitis vinifera sp.): association with antiradical activity // J. Food Composition and Analysis. 2005. N18. Pp. 375-386.

28. Parini S.P., Mazza G., Gatti M., Bavaresco L. Anthocyanin and aroma profiling of the «Albarossa» grapewine crossbreed (Vitis vinifera L.) and its parent varieties «Barbera» and «Nebbiolo di Dronero» // Vitis. 2010. Vol. 49, N3. Pp. 121-127.

29. Burdulis D., Janulis V., Milašius A., Jakštas V., Ivanauskas L. Method development for determination of anthocyanidin content in bilberry (Vaccinium myrtillus L.) fruits // J. Liquid Chrom. \& Related Technol. 2008. N31. Pp. 850864.

30. Вертикова Е.К., Ходаков И.В., Левицкий А.П. Метод определения хлорогеновой кислоты // Вісник стоматології. Спец. випуск. 2010. Т. 73, N5. С. 2-5.

31. Патент 80597 (UA). Спосіб ідентифікації поліфенолів в рослинних екстрактах / І.В. Ходаков, О.А. Макаренко, А.П. Левицький. 2012.

32. Ходаков И.В. Способ идентификации полифенолов в растительных экстрактах // Вісник стоматології. Спец. випуск. 2012. Т. 80, №7. С. 42.

33. Jensen J.S., Blachez B., Egebo M., Meyer A.S. Rapid extraction of polyphenols from red grapes // Am. J. Enol. Vitic. 2007. Vol. 58, N4. Pp. 451-461.

34. Corrales M., Toepfl S., Butz P., Knorr D., Tauscher B. Extraction of anthocyanins from grape by-products assisted by ultrasonic, high hydroststic pressure or pulsed electric fields: a comparison // Inn. Food. Sci. Emerg. Tech. 2008. N9. Pp. 85-91.

35. Pomar F., Novo M., Masa A. Varietal differences among the anthocyanins profiles of 50 red table grape cultivars studied by high performance liquid chromatography // J. Chrom. A. 2005. N1094. P. 34-41.

36. Suárez R., Monages M., Bartolomé B., Gómez-Cordovés C. Phenolic composiyion and colour of Vitic vinifera L. cv Merlot wines from different vintages and aging time in bottle // Ciência Téc. Vitic. 2007. Vol. 22, N2. Pp. 35-44.

37. Oberholster A., Botes M.-P., Lambrechts M. Phenolic composition of Cabernet-Sauvignin (Vitis vinifera) grapes during ripening in four South African winegrowing regions // J. Int. Sci. Vigne Vin, special issue Macrowine. June, 2010. Pp. 33-40.

38. Cho M.J., Howard L.R., Prior R.L., Clark J.R. Flavonoid glycosides and antioxidant capacity of various blackberry, blueberry and red grape genotypes determined by high-performance liquid chromatography/mass spectrometry // J. Sci. Food Agric. 2004. N84. Pp. 1771-1782.

39. Berente B., Reichenbächer M., Danzer K. Improvement of the HPLC analysis of anthocianins in red wines by use of recently developed columns // Fresenius J. Anal. Chem. 2001. N371. Pp. 68-72.

40. Radovanović B., Radovanović A. Free radical scavering activity and anthocyanin profile of Cabernet Sauvignon wines from the Balkan region // Molecules. 2010. N15. Pp. 2113-4226.

41. Flamini R., Tomasi D. The anthocyanin content in berries of the hybrid grapes cultivars Clinton and Isabella // Vitis. 2000. Vol. 39, N2. Pp. 79-81.

42. He J.-J., Liu Y.-X., Pan Q.-H., Cui X.-Y., Duan Ch.-Q. Different profiles of the skin and the pulp of Yan73 (Muscat Hamburg x Alicante Bouschet) grapes berries // Molecules. 2010. N15. Pp. 1141-1153.

43. Dionex Corporation (Thermo Science) Application Note 281: Rapid and sensitive determination of anthocyanins in bilberry using UHPLC. Sunnyvale, CA, USA. 2011. LPN 2848 PDF 7/11 (www.dionex.com).

Поступило в редакциюю 8 апреля 2013 г.

После переработки 17 июня 2013 г.

Khodakov I.V. THE USE OF WINE CABERNET-SAUVIGNON FOR THE DETERMINATION OF IDENTIFICATION PARAMETERS OF ANTHOCYANIDIN 3-O-GLUCOSIDES IN ANALYSIS OF ANTHOCYANIN COMPOSITION IN BILBERRY FRUIT PASTE

The Institute of Stomatology of National Academy of Medicine Sciences of Ukraine, Rishelievskaya str., 11, Odessa, 65026 (Ukraine),e-mail: hodakovigor@gmail.com

The ability to use wine Cabernet-Sauvignon (Vitis vinifera L.) to get parameters of 3-O-glucosides of delphinidin, cyanidin, petunidin, peonidin and malvidin for the identification of these anthocyanins in bilberry fruit paste (Vaccinium myrtillus L.) by HPLC was examined. The known sequence of anthocyanin peaks in chromatograms of bilberry fruit extracts using the 
reversed-phase chromatographic columns of C18 type at $530 \mathrm{~nm}$ allows to use identified 3-O-glucosides as markers for the identification of other anthocyanidin glycosides (galactosides and arabinosides) in bilberry fruit paste.

Keywords: wine Cabernet-Sauvignon, Vaccinium myrtillus, bilberry fruit paste, HPLC, anthocyanins, 3-O-glucosides of anthocyanidins.

\section{References}

1. Su Z. Pharmaceutical Crops, 2012, no. 3, pp. 7-37.

2. Levitskii A.P., Osipenko S.B., Tsisel'skii Iu.V., Dem'ianenko S.A., Makarenko O.A., Selivanskaia I.A. Fitoterapija. Chasopys, 2009, no. 3, pp. 26-30. (in Russ.).

3. Burdulis D., Ivanauskas L., Dirsè V., Kazlauskas S., Ražukas A. Medicina (Kaunas), 2007, vol. 43, no. 12, pp. 971-977.

4. Burdulis D., Šarkinas A., Jasutieneė I., Stackevičiene E., Nikolajevas L., Janulis V. Acta Poloniae Pharmaceutica Drug Res., 2009, vol. 66, no. 4, pp. 399-408.

5. Jovančević M., Balijagić J., Menković N., Šavikin K., Zdunić G., Janković T., Dekić-Ivanković M. J. Med. Plants Res., 2011, vol. 5, no. 6, pp. 910-914.

6. Rimpapa Z., Toromanovic J., Tahirovic I., Šapčanin A., Sofic E. Bosnian J. Basic Med. Sciences, 2007, vol. 7, no. 2, pp. 119-122.

7. Lätti A.K., Riihinen K.P., Kainulainen P.S. J. Agricult. and Food Chemistry, 2008, no. 56, pp. 190-196.

8. Burdulis D., Ivanauskas L., Jakštas V., Janulis V. Medicina (Kaunas), 2007, vol. 43, no. 7, pp.568-574.

9. Veres B.V., Dorica B. J. Horticulture, Foresty and Biotechnology, 2011, vol. 15, no. 3, pp. 94-98.

10. Saprykin L.V. Vysokoeffektivnaia zhidkostnaia khromatografiia. [High performance liquid chromatography]. Khar'kov, 2007, 228 p. (in Russ.).

11. Deineka V.I., Grigor'ev A.M., Staroverov V.M., Borzenko O.N. Khimiia prirodnykh soedinenii, 2003, no. 2, pp. $137-139$. (in Russ.).

12. Deineka V.I., Grigor'ev A.M. Zhurn. analit. khimii, 2004, vol. 59, no. 3, pp. 305-309. (in Russ.).

13. Deineka V.I., Grigor'ev A.M. Zhurn. fizich. Khimii, 2004, vol. 78, no. 5, pp. 923-926. (in Russ.).

14. Deineka V.I., Grigor'ev A.M., Deineka L.A., Shaposhnik E.I., Staroverov V.M. Zavodskaia laboratoriia. Diagnostika materialov, 2006, vol. 72, no. 3, pp. 16-20. (in Russ.).

15. Wulf L.W., Nagel C.W. Am. J. Enol. Vitic., 1978, no. 29, pp. 42-49.

16. Heier A., Blaas W., Droß A., Wittkowski R. Am. J. Enol. Vitic., 2002, no. 53, pp. 78-86.

17. Flamini R. Mass spectrometry Reviews, 2003, no. 22, pp. 218-250.

18. He F., Mu L., Yan G.-L., Liang N.-N., Pan Q.-H., Wang J., Reeves M.J., Duan Ch.-Q. Molecules, 2010, no. 15, pp. 9057-9091.

19. Hohnová B., Štaviková L., Karásek P. Czech J. Food Sci., 2008, vol. 26. Special Issue. Ph. S39-S42.

20. Berente B., Garcia D. De la C., Reichenbächer M., Dancer K. J. Chrom. A., 2000, no. 871, pp. 95-103.

21. Durst R.W., Wrolstad R.E. Currant protocols in food analytical chemistry. New York, 2001. Unit F1.3.1-1.3.13.

22. Boss P.K., Davis Ch., Robinson S.P. Plant Physiol., 1996, no. 111, pp. 1059-1066.

23. Revilla E., Ryan E.M. J. Chrom. A., 2000, no. 881, pp. 461-469.

24. Revilla E., Garcia-Beneytez E., Cabello F., Martin-Ortega G., Ryan J.-M. J. Chrom. A., 2001, no. 915, pp. 53-60.

25. Muńoz S., Mestres M., Busto O., Guasch J. Analitica Chimica Acta, 2008, no. 628, pp. 104-110.

26. Pati S., Liberatore M.T., Gambacorta G., Antonacci D., La Notte E. J. Chrom. A., 2009, no. 1216, pp. 3864-3868.

27. Kallithraka S., Mohdaly A. A.-A., Markis D.P., Kefalas P. J. Food Composition and Analysis, 2005, no. 18, pp. 375-386.

28. Parini S.P., Mazza G., Gatti M., Bavaresco L. Vitis, 2010, vol. 49, no. 3, pp. 121-127.

29. Burdulis D., Janulis V., Milašius A., Jakštas V., Ivanauskas L. J. Liquid Chrom. \& Related Technol., 2008, no. 31, pp. $850-864$.

30. Vertikova E.K., Khodakov I.V., Levitskii A.P. Visnyk stomatologii'. Spec. vypusk, 2010, vol. 73, no. 5, pp. 2-5. (in Ukr.).

31. Patent 80597 (UA).2012 (in Ukr.).

32. Khodakov I.V. Visnyk stomatologii'. Spec. Vypusk, 2012, vol. 80, no. 7, pp. 42. (in Ukr.).

33. Jensen J.S., Blachez B., Egebo M., Meyer A.S. Am. J. Enol. Vitic., 2007, vol. 58, no. 4, pp. 451-461.

34. Corrales M., Toepfl S., Butz P., Knorr D., Tauscher B. Inn. Food. Sci. Emerg. Tech., 2008, no. 9, pp. 85-91.

35. Pomar F., Novo M., Masa A. J. Chrom. A., 2005, no. 1094, pp. 34-41.

36. Suárez R., Monages M., Bartolomé B., Gómez-Cordovés C. Ciência Téc. Vitic., 2007, vol. 22, no. 2, pp. 35-44.

37. Oberholster A., Botes M.-P., Lambrechts M. J. Int. Sci. Vigne Vin, special issue Macrowine, 2010, June, pp. 33-40.

38. Cho M.J., Howard L.R., Prior R.L., Clark J.R. J. Sci. Food Agric., 2004, no. 84, pp. 1771-1782.

39. Berente B., Reichenbächer M., Danzer K. Fresenius J. Anal. Chem., 2001, no. 371, pp. 68-72.

40. Radovanović B., Radovanović A. Molecules, 2010, no. 15, pp. 2113-4226.

41. Flamini R., Tomasi D. Vitis, 2000, vol. 39, no. 2, pp. 79-81.

42. He J.-J., Liu Y.-X., Pan Q.-H., Cui X.-Y., Duan Ch.-Q. Molecules, 2010, no. 15, pp. 1141-1153.

43. Dionex Corporation (Thermo Science) Application Note 281: Rapid and sensitive determination of anthocyanins in bilberry using UHPLC. Sunnyvale, CA, USA. 2011. LPN 2848 PDF 7/11 (www.dionex.com). 